\title{
Self-extubation after major trauma: another trauma?
}

\author{
Hye Jung Cho ${ }^{1}$, Sung Woo Jang ${ }^{2}$, Pil Young Jung ${ }^{2}$ \\ ${ }^{1}$ Department of Surgery, Bundang CHA Medical Center, CHA University, Bundang, \\ ${ }^{2}$ Department of Surgery, Yonsei University Wonju College of Medicine, Wonju Severance \\ Christian Hospital, Trauma Center, Wonju, Korea
}

Received September 9, 2021

Revised September 16, 2021

Accepted October 8, 2021

Correspondence to

Pil Young Jung

Department of Surgery, Yonsei

University Wonju College of Medicine

Wonju Severance Christian Hospital,

Trauma Center, 20 Ilsan-ro, Wonju

26426, Korea

Tel: +82-33-741-0882

Fax: +82-33-741-0574

E-mail: surgery4trauma@yonsei.ac.kr
Self-extubation can lead to detrimental outcomes for the patient. Complications that result from self-extubation range from laryngeal injury, respiratory distress, arrhythmia, pneumonia, to even death. With respect to patient safety, not only is prevention of self-extubation one of the most important goals in all intensive care units around the world, but also it is one of the most common mishaps in the area of intensive care. Since self-extubation and consequent re-intubation are unexpected events, they can embarrass the medical staff and negatively affect the treatment choice, and consequently, require other invasive procedures that may not have been necessary. The most important thing for patients exposed to self-extubation is to keep in mind the presence of airway damage, which can be confirmed through our experience as described here, through repeated re-intubations and eventually tracheostomy.

Key Words: Intratracheal intubation, Airway extubation, Tracheostomy, Mechanical ventilators

\section{Introduction}

Prevention of self-extubation is one of the most important and basic preparations in all the intensive care units (ICU) for patient safety and better prognosis. Unfortunately, self-extubation coupled with accidental extubation constitute unplanned extubation, which are surprisingly common in ICUs $(1,2)$. Compared to accidental extubation, self-extubation is far more common and accounts for more than half of all unplanned extubations (3). Many complications are caused by unplanned removal of the endotracheal tube, including self-intubation (3). Re-intubation, which is one of the poor prognostic factors in
ICU patients, has been reported to have been required in $28.5 \%$ to $74.7 \%$ of self-extubated patients (4-6). Among the complications of self-extubation and consequent re-intubation, airway injury results in edema, ulceration, and granulation that may require other invasive procedures (e.g., tracheostomy). With the patients who have experienced self-extubation and re-intubation, clinicians should always keep in mind the potential for airway injury. Hasty extubation needs to be avoided and these patients have to be assessed for airway injuries. This report highlights the harmful effects of self-extubation and repeated re-intubation in trauma patients.

(c)This is an Open Access article distributed under the terms of the Creative Commons Attribution Non-Commercial License (http://creativecommons.org/licenses/by-nc/4.0) which permits unrestricted noncommercial use, distribution, and reproduction in any medium, provided the original work is properly cited.

Copyright (C) 2021 Korean Association for Research, Procedures and Education on Trauma. All rights reserved. 


\section{Case presentation}

A fifty-one-year-old female was transferred to our institution after a traffic accident. The patient felt drowsy and complained of left chest wall pain. Her initial blood pressure (BP) and heart rate were $115 / 68 \mathrm{mmHg}$ and 90 beats/min. Flail chest with multiple rib fractures, traumatic hemothorax, multiple organ contusions (including lung, heart and kidney), spleen laceration with extravasation of contrast, and superior ramus fracture were diagnosed in computed tomography exams (Fig. 1).

Initial hemoglobin was $10.3 \mathrm{~g} / \mathrm{dL}$ (normal range; 12.0 $16.0 \mathrm{~g} / \mathrm{dL}$ ), but it plummeted to $8.7 \mathrm{~g} / \mathrm{dL}$ two hours after arrival and her BP was 92/49 mmHg. Emergency angiographic embolization of the splenic artery was done, and the patient was admitted to ICU.

On hospital day (HD) three, she complained of dyspnea, with $70 \%$ saturation and haziness in both lung fields in the chest X-ray (CXR) (Fig. 2A). Intubation was done using a $7.5 \mathrm{~mm}$ endotracheal tube. On HD 4, twenty-two hours
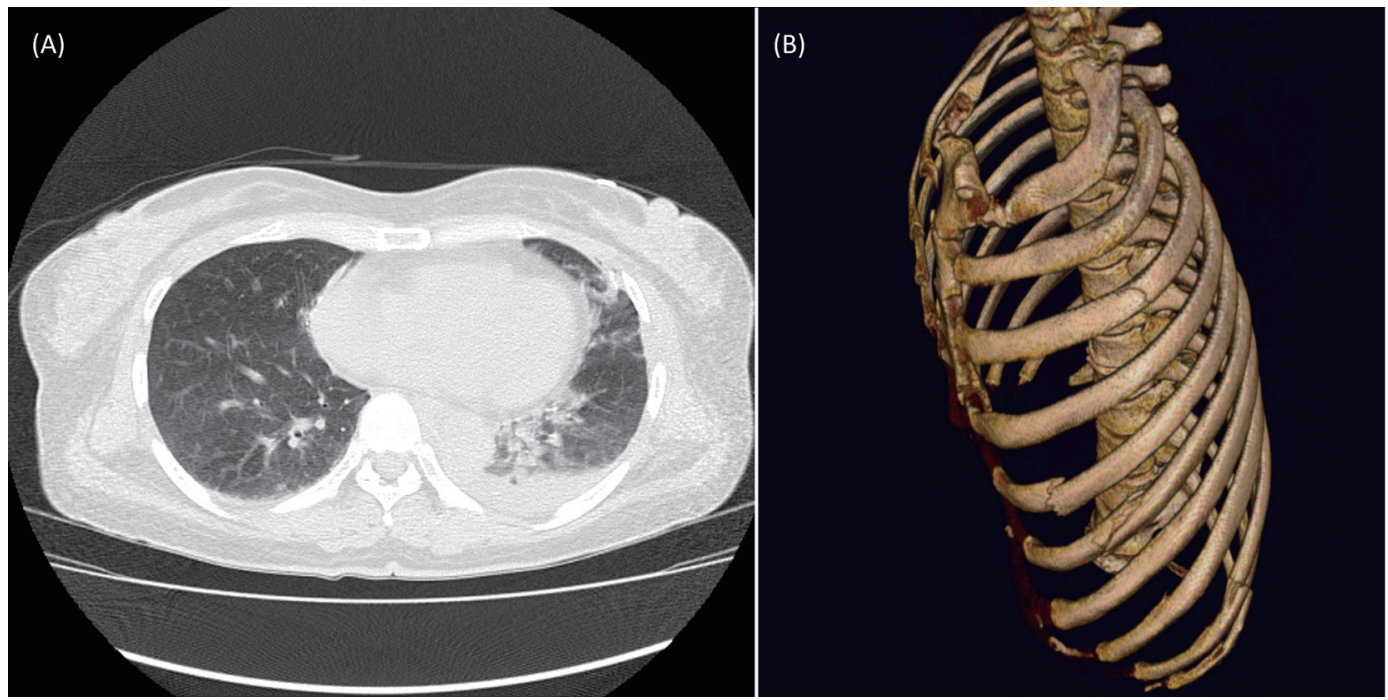

Fig. 1. Chest computed tomography on hospital day 1. (A) Left lung contusion and hemothorax. (B) Left multiple rib fractures.
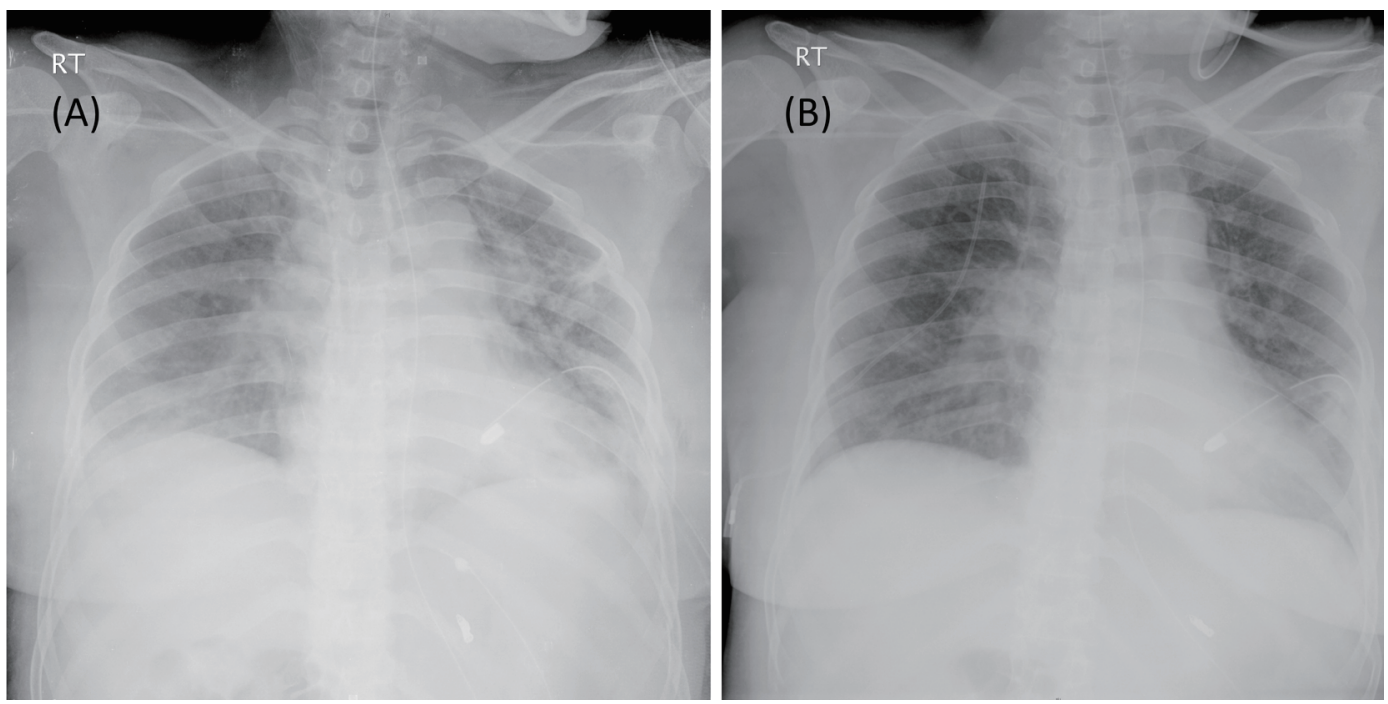

Fig. 2. Chest X-ray of the patient. (A) Hospital day 3, prior to the first intubation with haziness in both lung fields, chest tube inserted state in left lung. (B) Hospital day 10, immediately after the second extubation, showing improved lung status than the first intubation. 

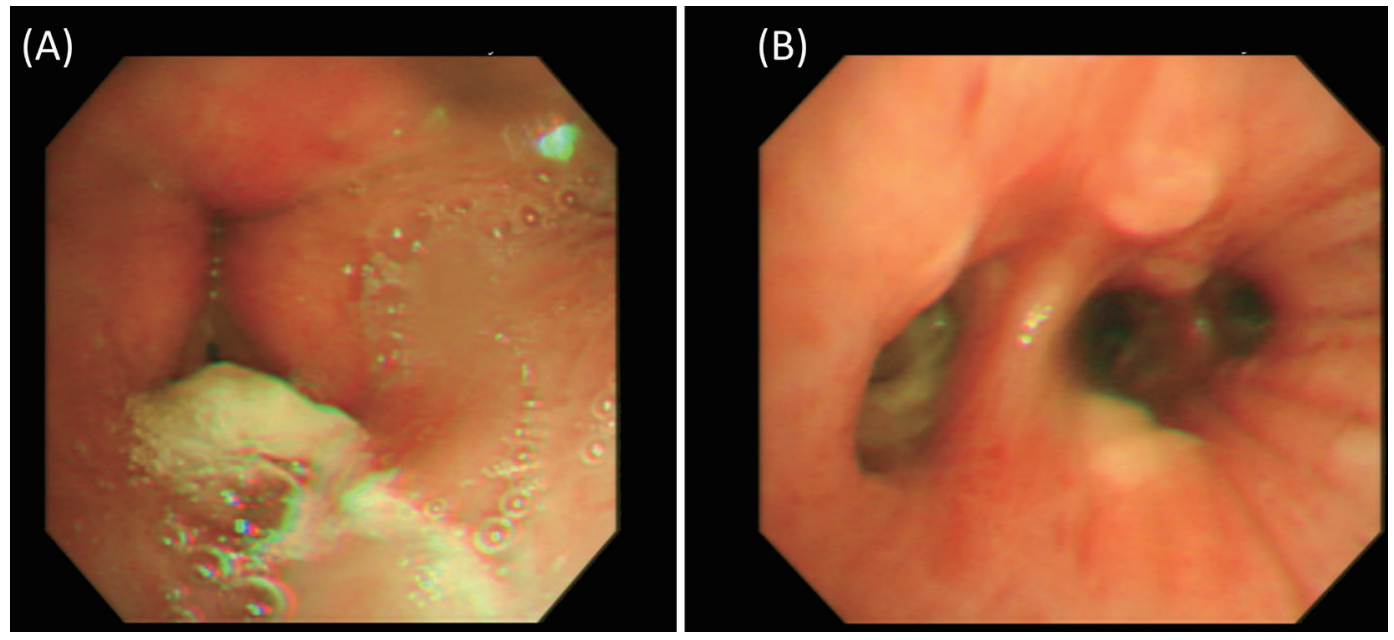

Fig. 3. Bronchoscopy after the fourth intubation. (A) Edematous vocal cord with whitish exudate at posterior commissure. (B) Exudate with multiple patch nodular lesions .

after first intubation, the patient self-extubated her endotracheal tube. Immediate re-intubation was done because post-extubation stridor was observed. On HD 10, with alert mental status, stable vital signs, and improved CXR findings, planned extubation was done (Fig. 2B).

Nine hours after extubation, the patient complained of severe dyspnea again. In arterial blood gas analysis, $\mathrm{pCO}_{2}$ was $51.7 \mathrm{mmHg}$, and the third intubation was done. On HD 18, after confirming no respiratory distress by T-piece weaning trial and clear lung findings in CXR, the third extubation was done. Immediately after extubation, however, respiratory distress with stridor was observed again. Twenty-five minutes after the third extubation, the fourth intubation was done. Bronchoscopy was performed after consultation with the pulmonologist, and it revealed edematous vocal cord with whitish exudate at posterior commissure (Fig. 3A) and the trachea was covered with exudate with multiple patch nodular lesions (Fig. 3B). In order to resolve the laryngeal edema, tracheostomy was performed. After rehabilitation, tracheostomy was sealed off on HD 47 and she was discharged on HD 50 without any further pulmonary complications.

\section{Discussion}

The incidence rates for unplanned extubation that consists of self-extubations and accidental extubations were reported to be as high as $35.8 \%$ in a recent systematic review (7). Complications that result from self-extubation range from laryngeal injury, respiratory distress, arrthymia, aspiration pneumonia, and even death (1). With the complication of self-extubation itself, a high percentage of self-extubated patients require re-intubation, which leads to a poor prognosis for the patient (4-6). Consequently, prevention of unplanned extubation is the most important strategy in the ICU, and includes identifying patients vulnerable to self-extubation, prescribing appropriate sedatives, implementing a training system for staff, and appropriately shortening of the duration of mechanical ventilation.

Intubation itself is a risk factor for airway injury. Laryngeal injury is observed in $73 \%$ of intubated patients in fiberoptic endoscopic evaluation (8), and one of the primary causes of respiratory distress after extubation is laryngeal edema (9). Jaber et al showed a significant difference in extubation failure rate between those who did and did not develop post-extubation stridor (PES), and a positive correlation between a history of self-extubation and PES (9).

Self-extubation is a troublesome and embarrassing situation in ICU. Although prevention is the best strategy, it is also true that self-extubation is common. Therefore, clinicians should be able to respond appropriately when self-extubation occurs. Careful decisions about extubation and awareness of the possibility of an airway injury are paramount. In this report, fiberoptic evaluation for airway injury was performed after the fourth intubation. Earlier fiberoptic evaluation might be necessary for prompt de- 
tection of laryngeal injury. Patients with risk factors for laryngeal injury who may show extubation failure, such as emergency intubation, higher Acute Physiology and Chronic Health Evaluation II scores, long duration of intubation, self-extubation history, and presence of underlying trauma may require further evaluation prior to extubation $(8,9)$.

\section{Conflict of interest}

No potential conflict of interest relevant to this article was reported.

\section{References}

1. Cohn JE, Touati A, Lentner M, Weitzel M, Fisher C, Sataloff RT. Self-extubation laryngeal injuries at an academic tertiary care center: a retrospective pilot study. Ann Otol Rhinol Laryngol. 2017;126(7):555-60.

2. Singh PM, Rewari V, Chandralekha AMK, Arora MK, Trikha A. A retrospective analysis of determinants of self-extubation in a tertiary care intensive care unit. J Emerg Trauma Shock. 2013;6(4):241-5.

3. Lucchini A, Bambi S, Galazzi A, Elli S, Negrini C, Vaccino $S$, et al. Unplanned extubations in general intensive care unit: A nine-year retrospective analysis.
Acta Biomed. 2018;89(7-S):25-31.

4. de Lassence A, Alberti C, Azoulay E, Le Miere E, Cheval $C$, Vincent $F$, et al. Impact of unplanned extubation and reintubation after weaning on nosocomial pneumonia risk in the intensive care unit: a prospective multicenter study. Anesthesiology. 2002;97(1):148-56.

5. Kiekkas P, Aretha D, Panteli E, Baltopoulos GI, Filos KS. Unplanned extubation in critically ill adults: clinical review. Nurs Crit Care. 2013;18(3):123-34.

6. Pandey CK, Singh N, Srivastava K, Alka R, Baronia A, Agarwal A, et al. Self-extubation in intensive care and re-intubation predictors: a retrospective study. J Indian Med Assoc. 2002;100(1):11, 14-6.

7. da Silva PS, Fonseca MC. Unplanned endotracheal extubations in the intensive care unit: systematic review, critical appraisal, and evidence-based recommendations. Anesth Analg. 2012;114(5):1003-14.

8. Tadié JM, Behm E, Lecuyer L, Benhmamed R, Hans $\mathrm{S}$, Brasnu D, et al. Post-intubation laryngeal injuries and extubation failure: a fiberoptic endoscopic study. Intensive Care Med. 2010;36(6):991-8.

9. Jaber S, Chanques G, Matecki S, Ramonatxo M, Vergne C, Souche B, et al. Post-extubation stridor in intensive care unit patients. Risk factors evaluation and importance of the cuff-leak test. Intensive Care Med. 2003;29(1):69-74. 